\title{
AS LETRAS COMO UNIDADES HISTÓRICAS NA CONSTRUÇÃO DO DISCURSO
}

\author{
Dagoberto Buim Arena*
}

\begin{abstract}
RESUMO: Este artigo propõe a concessão de estatuto de unidade portadora de sentido aos grafemas, constituintes de palavras em situações de construções discursivas, tal como Vigostki deu ao fonema esse estatuto na palavra oral. Procura-se analisar também essas unidades em manifestaçōes singulares em atos de apropriação da linguagem escrita, com base em dados criados por uma criança de 6 anos, em uma situação discursiva. Para a realização da tarefa, foram importantes também os estudos bakhtinianos a respeito do papel do outro nas relaçōes com a linguagem. Uma vez que as análises indicaram aproximações ortográficas a registros encontrados no português antigo, foram utilizadas pesquisas de gramática histórica dessa língua. As conclusões apontam a diversidade de fontes de referência para a seleção, pela criança, das letras, conforme suas funções na composição da palavra.
\end{abstract}

Palavras-chave: Alfabetização. Oralidade e escrita. Funções de letras. Ortografia do português. Discurso.

\section{LETTERS AS HISTORICAL UNITS IN THE CONSTRUCTION OF SPEECH}

ABSTRACT: This paper proposes we grant graphemes - the constituents of words in situations of discursive constructions - the status of meaning carrying units, in much the same way Vigotski granted

Doutorado em Educação e professor assistente do Departamento de Didática e do Programa de Pós-Graduação em Educação da Universidade Estadual Paulista (Unesp, campus de Marília). E-mail: arena@marilia.unesp.br 
the phoneme such status in relation to the spoken word. This paper also seeks to analyze these units in singular manifestations in acts of appropriation of the written language, based on data created by a six-year-old child in a discursive situation. To perform this task, we also referred to Bakhtinian studies on the role of the other in our relation with language. Since the analysis indicated spelling approximations to records found in old Portuguese, historical grammar research of Portuguese was also used. The findings indicate the diversity of reference sources for letter selection by the child, according to its function in the composition of the word.

Key words: Literacy. Orality and literacy. Functions of letters. Spelling of Portuguese. Discourse.

\section{Introdução}

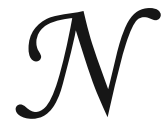

este trabalho serão analisadas situações nas quais uma criança toma decisões para escolher letras na construção de palavras em um enunciado, durante o seu processo de alfabetização. A indagação básica que norteia a análise refere-se às possibilidades de a criança orientar-se pela função da letra e pela internalização de conhecimentos sobre o uso da língua escrita na relação com o outro. A premissa de origem fundamenta-se na hipótese de que uma criança parece testar e experimentar o emprego de letras de acordo com a função que estas podem exercer na constituição gráfica e na constituição dos sentidos de uma palavra em um enunciado. Ao analisar e tentar compreender as manifestações escritas de uma criança, o pesquisador encontrou possíveis semelhanças entre composições gráficas entre as palavras por ela escritas e grafias do português entre os séculos XII e XVI. Para articular o pressuposto inicial, a de entender a letra como unidade portadora de sentido, e enveredar para as análises posteriores, será necessário estabelecer, desde já, os aportes teóricos de apoio.

Para definir alguns pontos da premissa de origem que aqui será desenvolvida, seria necessário aprofundar, rapidamente, comentários sobre a função da letra na constituição da palavra e do enunciado, com o apoio das pesquisas realizadas por Vigotski (2001), especificamente de uma de suas teses. Trata-se da função do fonema e da função da letra, no universo da criação de sentidos pela língua escrita ou oral. Como uma unidade da palavra, a letra teria, na sua construção, uma função a cumprir. Essas funções, de acordo com a tese deste artigo, seriam descobertas pela própria 
criança ao elaborar os dados fornecidos pelo docente e pelos outros - adultos ou crianças - que com ela mantêm relações mediadas pela língua escrita. Entretanto, para alicerçar esse ponto de vista, convém destacar que, para Vigotski (2001, p. 318), "ela é a álgebra da fala, uma forma mais difícil e complexa de linguagem intencional e consciente", e, para ser internalizada, é preciso que a criança tenha consciência de suas funções.

Relata-se, mais adiante, pesquisa realizada com crianças do primeiro ano do ensino fundamental, com aproximadamente 6 a 7 anos de idade, em uma escola da rede municipal de ensino da cidade de Marília, no interior do estado de São Paulo (Brasil). No recorte aqui apresentado, será analisada uma situação de escrita de uma aluna com 6 anos de idade - Berenice (nome fictício) - que escreve para uma criança internada para tratamento em um hospital público de São Luís, Maranhão (Brasil), aluna com frequência temporária em uma classe hospitalar.

A base teórica de coleta de dados apoia-se nos conceitos de contexto de pesquisa de Graue e Walsh (2003) e de linguagem egocêntrica no processo discursivo (VIGOTSKI, 2001; SMOLKA, 1993), e a base de análise ampara-se nos princípios da microgenética (GOES, 2000), na teoria da enunciação de Bakhtin (2003) e nos estudos históricos de Williams (1975), Desbordes (1995), Sampson (1996) e Huber (2006).

A delimitação da situação de pesquisa tem como referência o conceito de contexto de pesquisa (GRAUE; WALSH, 2003), entendido como uma situação real e concreta, claramente situada social e historicamente, com envolvimento de sujeitos em interação. Não se trata de situação laboratorial, mas de uma situação em que a criança efetivamente lança suas palavras em direção ao outro: há um aluno que escreve e outro que, a distância, orienta a ação do primeiro, e, no ato da criação, há uma estudante de graduação em Pedagogia, bolsista de um projeto de extensão universitária, que interfere na organização dos enunciados lançados de um em direção ao outro, ambos à espera dos atos discursivos.

No presente estudo, a importância da análise se desloca para o modo como a criança, pela escrita, se relaciona com a cultura de seu tempo, do seu lugar, com a cultura e com o lugar do outro. A perspectiva é a de entendê-la como um ser que se apropria da escrita como um bem cultural, em um momento histórico de seu percurso ontogenético. A geração dos dados também incorpora os pressupostos de Bakhtin (2003) a respeito da natureza social da linguagem e de seu lugar na interação entre os homens, 
porque é necessário entender a palavra escrita, constitutiva de enunciado, como um signo ideológico e como uma unidade na construção dialógica que reverberam, também, o estatuto da letra como unidade sensível no universo da composição do discurso. A situação de escolha e de decisão por parte de uma criança, no momento da escrita de uma carta para o outro, não se configura como ato banal por situar-se no universo das relaçóes da sua consciência com a consciência do outro, por meio de palavras, de signos verbais, de enunciados amalgamados por combinações de significação, de sentido e, também, de letras.

Na situação real, de tentativas de apropriação da língua escrita como instrumento de comunicação de constituição do pensamento, as letras, as palavras e o próprio enunciado ganham funções plurais, em vez do engessamento técnico a apenas uma delas: a relativa relação fonema-grafema. Como uma unidade na palavra, a letra teria funçôes por preservar com ela os traços de significado constituintes do todo. Vigotski verificou a importância da função nas manifestações de linguagem, porque com elas se organizariam as próprias estruturas dessas manifestações. Duas perguntas iniciais a respeito podem se elaboradas: Qual seria a importância do conceito de função nas manifestações de linguagem para Vigotski? Quais seriam essas manifestações? Como estudioso da linguagem, ele reconhece o fonema como unidade do todo que envolve o aspecto fônico e o semântico da palavra oral, mas destaca que somente se mantém como unidade se for constituinte da palavra plena; fora dela, fora do enunciado, o fonema deixa de ser unidade e fica reduzido a um elemento:

Assim, a unidade da fala vem a ser no som uma nova concepção não de um som isolado, mas de um fonema, isto é, uma unidade fonológica indecomponível, que conserva todas as propriedades básicas de todo o aspecto sonoro da fala com função de significação. Tão logo o som deixa de ter significação e se destaca do aspecto sonoro da fala, perde imediatamente todas as propriedades inerentes à fala humana. Por isso, tanto em termos linguísticos quanto psicológicos só pode ser fértil o estudo do aspecto fônico da fala que aplique o método de sua decomposição em unidades preservadoras das propriedades inerentes à fala, enquanto propriedades dos aspectos fônico e semântico. (VIGOTSKI, 2001, p. 15)

A letra na palavra escrita, como o fonema, na oral, poderia ser tanto uma unidade quanto um elemento, se for aplicado o mesmo raciocínio descortinado por Vigotski. Seria unidade se estivesse vinculada a uma palavra, a 
um enunciado ou a um discurso, ou seria apenas um elemento se destituída de sentido e isolada do enunciado. O significado da palavra e o sentido construído confeririam à letra o seu estatuto de unidade. Fora disso, estaria destinada a ser um elemento. Conceder a ela o estatuto de letra como unidade, portanto com função, é lidar com a complexidade da aprendizagem da língua escrita. Por essa razão, afirma Vigotski (op. cit., p. 313) que, "como mostram as investigações, é exatamente esse lado abstrato da escrita, o fato de que esta linguagem é apenas pensada e não pronunciada, que constitui uma das maiores dificuldades com que se defronta a criança no processo de apreensão da escrita”.

O princípio norteador deste artigo, e da pesquisa por ele relatada, sugere que as letras, pelas razões encontradas em Vigotski (op. cit.), não teriam apenas a função única e incontestável de representar o fonema, mas, como unidade, participaria da construção dos sentidos e, por essa mesma razão, pode exercer funções múltiplas, que levam uma criança, no processo inicial de alfabetização, a fazer escolhas que não coincidem com a expectativa docente, sempre à espera de uma correspondência grafema-fonema convencional.

Os estudos de Desbordes (1995), na área da linguística, especificamente do latim, enveredam para conclusóes similares à de Vigotski em relação ao conceito de letra como unidade portadora de sentido (apesar de não fazer a distinção entre elemento e unidade), e como razão explicativa para manifestaçôes de algumas grafias das línguas romanas, motivo pelo qual as crianças podem escrever orientadas pela letra como unidade de sentido, em vez de se orientarem pela representação fonêmica. Segundo Desbordes (op. cit., p. 189),

Podem-se utilizar as unidades da escrita para manifestar a diferença entre duas palavras; pode-se também utilizá-las para manifestar semelhanças, parentescos reais ou supostos. A unidade, então, não é mais concebida como um puro elemento distintivo, mas como um elemento portador de uma parcela de sentido que convém conservar em combinaçôes diversas.

Como Vigotski, Desbordes aposta na letra como portadora de parte do sentido do todo, com funçôes diversas da estritamente técnica que inclui a relação grafema/fonema tão presente nos procedimentos de alfabetização inicial e nos suportes das teorias pedagógicas, que defendem o requisito do domínio da consciência fonológica para a alfabetização. 
Tomo como pressuposto, neste trabalho, o argumento de que a letra não se tornaria apenas um sinal gráfico ao vincular-se a uma palavra, porque esta, ao ser decomposta em unidades, transforma a letra em uma efetiva unidade por preservar também com ela os valores ideológicos nela impregnados (BAKHTIN, 2003).

A situação de criação dos enunciados na pesquisa aqui relatada envolveu, nesse contexto, os aspectos abordados por Graue e Walsh (2003), por Bakhtin (2003) e Vigotski (2001) até aqui. Criada a situação e com ela os dados, o olhar orientado pela microgênese (GÓES, 2000) deverá tentar analisar algumas escolhas de letras e algumas configurações gráficas de palavras. Esse olhar permite ao pesquisador anunciar, antes ainda das conclusōes, as escolhas imprevisíveis, mas outro aspecto a considerar será a impressionante coincidência em algumas composiçôes gráficas com fatos históricos do português escrito, ou das línguas neolatinas de modo geral. Para analisar esses dados foi necessário recorrer a estudiosos das línguas românicas (WILLIAMS, 1975; DESBORDES, 1995; SAMPSON, 1996; HUBER, 2006).

\section{Análise dos dados}

Relembremos o contexto de pesquisa: Berenice, da escola de Marília, escreve para Terezinha, criança provisoriamente presente em uma classe hospitalar de um hospital público de São Luís (Maranhão, Brasil). A carta construída a uma bolsista foi concluída com os enunciados a seguir, acompanhados por sua adequação convencional aos padrões linguísticos do português brasileiro contemporâneo.

Oi t tudo b $-e$ ? (letra e marcada por um til.)

(Oi, tudo bem?)

$O$ di vo ce istu da?

(Onde você estuda?)

Você teirme?

(Você tem irmão?)

Qomu ceir megão?

(Como se chama seu irmão?) 


\section{bgo no di abco}

(beijo e um grande abraço).

Berenice, nesta situação singular de construção de um enunciado, parece fazer, em alguns casos que adiante serão comentados, escolhas de letras para escrever palavras tal como fizeram os usuários da língua portuguesa no início de sua constituição, por volta dos séculos XII a XVI, como língua derivada dos dialetos falados e escritos no norte da Espanha, especificamente da região de Leon e da Galícia. Ao verificar como as crianças brasileiras escrevem, nos atos de apropriação e de objetivação do português brasileiro, talvez fosse de interesse investigativo não apenas considerar a grafia atual como referência, mas também as variações gráficas do português e do galego antigos. Da escrita inicial de Berenice e de suas respostas à bolsista, pode ser possível encontrar articulação com formas ancestrais da escrita do português.

\section{Oi T, tudo b - e? (til sobre a vogal e) \\ (Oi, tudo bem?).}

A consoante $\mathrm{M}$ desaparecera no latim, transformada em $\mathrm{N}$, no final da palavra, exceto nos monossílabos (WILLIAMS, 1975). A aluna reproduz em sua escrita a ausência histórica da letra $M$ do português moderno, no registro gráfico, e a substitui por uma marca indicadora de nasalização em E, ou seja, o til, utilizado nos dias atuais para representar a nasalização. É possível, ainda, inferir que Berenice se recusa a registrar a letra $M$, frequentemente utilizada para representar um fonema consonantal, para representar apenas um alofone vocálico de E. A criança opta por usar a letra E, mas complementa a grafia da palavra com um sinal herdado da tradição portuguesa, sem a preocupação com a convenção atual. A função da letra E sob o til na grafia - dois sinais associados, uma letra e um sinal não categorizado como letra, mas com função na composição gráfica da palavra - não é encontrado no português contemporâneo, oferecido à criança pela professora e pelos materiais escritos, nem revela a representação grafofonética a ela ensinada. A aluna recusa as duas orientações ao reativar as formas históricas diferenciadas de registro. Williams (1975, p. 34) afirma que, no período fonético da língua portuguesa, havia uma

Confusão de m, n, e til: ano e año por anno; cam -iho por caminho; cimco por cinco; grade por grande; hõe por home ou homem; h-uildade por 
humildade; meenesmo por m-eesmo (arcaico); pôho por ponho; poner por põer (arcaico); saom por são (de sanu-); senpre por sempre; $t$ - epo por tempo; emader por $\sim$ eader.

É necessário observar que na palavra $h$-uildade, e -eader (ou $\sim$ ua $=$ uma) o til ocupou a função da consoante $\mathrm{M}$ em vez de indicar apenas a nasalização da vogal, como frequentemente indicam as descrições linguísticas, como é o caso de $t$-empo, ou de $b-e$ grafado por Berenice.

Na sequência, a aluna aponta sua convicção no diálogo com a bolsista sobre o uso do til.

P: É assim mesmo que se escreve a palavra bem? Com a letra $b$ e a letra $e$ ? Berenice: É assim mesmo!

P: O que mais você gostaria de escrever para a T?

Berenice: Quero saber onde que ela estuda.

O uso da forma $b-e$ por Berenice, nesse momento, não indica a estabilidade de sua ortografia, porque poderá, em outro momento, utilizar outra forma de escrever a mesma palavra, como apontam os estudos de Abaurre (1997), e as afirmaçóes de Huber (2006) a respeito do português antigo. Segundo Huber (op. cit., p. 42 e 43) "é difícil observar num monumento linguístico e literário do português antigo uma grafia inteiramente uniforme. Uma e a mesma palavra aparece frequentemente no mesmo texto sob formas diferentes", da mesma forma que "é igualmente bem variado e inconsequente o uso de sinais ortográficos (como acentos, tiles, traços de união, apóstrofos) nos velhos manuscritos”. Convém destacar a utilização do adjetivo inconsequente por Huber. Inconsequente quer dizer desnecessário do ponto de vista fonético, porque "os acentos são muitas vezes empregados para representar vogais nasais; mas também se encontram em vogais não nasais" (idem, ibid., p. 4). O emprego do til sobre a vogal E, feito por Berenice, espelha a mesma grafia encontrada por Huber (2006, p. 44 e 45): "No fim de palavra, a vogal nasal é muitas vezes indicada por um m ou n: um, huum $=\sim$ uu, bom = bõ, bem ou bem $=$ b $\sim$ e $($ rima com qu $\sim$ e)" "b $\sim$ ees (plur. de bem)". Berenice recupera, neste caso, a grafia dessa mesma palavra, em certos documentos do português antigo.

Na sequência de sua carta, lança a pergunta em direção a Terezinha: $O$ di vo ce istu da? (onde você estuda?). A criança murmurava enquanto escrevia, conforme os apontamentos já feitos por Smolka (1993), ao comentar 
a ocorrência da linguagem egocêntrica (VIGOSTKI, 2001) em situações de escrita como ato discursivo.

Pesquisadora/bolsista: É assim mesmo que escreve a palavra onde? Só com a letra $o, d$ e $i$ ?

Berenice: É assim.

P: É assim mesmo? Não está faltando nada?

Berenice: Não.

P: A palavra você é separada mesmo? Está certo assim?

Berenice: Não.

P: Como é que se escreve então?

Berenice: Escreve tudo junto.

A bolsista tenta, embora sem êxito, ouvir da aluna os motivos pelos quais utilizou a palavra $o$ di sem marcas de nasalização e segmentada não convencionalmente. Ao escrever bem, marcou a vogal E com o sinal til que supostamente indica a nasalização, mas é possível inferir que reproduza registros históricos como elementos constituintes da cultura escrita do português. A hipótese de que haveria falta de padronização dos procedimentos praticados por Berenice pode ser alimentada pelo fato de ela deixar de agregar à letra $\mathrm{O}$, na palavra onde, o sinal til como fizera em bem (b-e; odi), mas essa ausência de marcação, apesar de serem vogais diferentes, também é registrada por Huber (2006, p. 44 e 45):

Muitas vezes o til ou o traço, que se emprega para representar a nasalação da vogal, é posto apenas na vogal seguinte ou falta todo e qualquer sinal de nasalação; ambas as coisas se devem com certeza a desleixos do escriba; por ex: boã em vez de bóa, $\mathrm{u} \sim \mathrm{u}=\sim \mathrm{uu}$ ou boa em vez de bõa ao lado da qual também se encontra bona; divisoes (1'192) = divisões. [e ainda] $m$ indica a nasal: em omde ao lado de onde<unde. [...] É provável que, a partir do emprego do $n$ para designar vogais nasaladas, se explique também a grafia ocasional do $n$ em vez de $m<m$ até antes de labiais.

Consideradas como pistas de ocorrências gráficas, essas grafias históricas podem ser comparadas com as de Berenice: ela também omite a marca til sobre a vogal $\mathrm{O}$ em $\boldsymbol{o}$ di, do mesmo modo como omitira o escriba na palavra boalbõa. A forma reconhecida como errônea naquele momento histórico é hoje utilizada como correta. Desaparece o emprego do til, de um sinal gráfico; 
a palavra se estabiliza em uma configuração gráfica, sem que a representação fonética seja determinante. A função fonética de representação do til se desvaneceu, neste caso. A respeito de $O$ di grafado por Berenice, pode-se dizer que se aproxima de longi citado por Huber (2006, p. 91) ao lado da grafia longe. Do mesmo modo, a sua escrita também neste caso reativa formas históricas de grafar. A respeito da segmentação da palavra onde e da palavra estuda, claramente a pergunta da bolsista induz a criança, pelo diálogo referenciado, ao reparo, porque há duas alternativas apenas: juntar ou separar. Na palavra estuda, destacada no diálogo a seguir, a criança experimenta alternativas de segmentação, com uso de critérios instáveis, do mesmo modo como faziam os copistas na Alta Idade Média (PARKES, 2002).

P: A palavra estuda. Por que você escolheu a letra $i$ para escrever?

Berenice: É porque eu gosto muito da letra $i$ !

P: Foi por isso então que você escreveu estuda com $i$ ?

Berenice: É.

P: E quando você escreveu a palavra estuda, por que você escreveu separado assim: estu da? Tem esse espaço aqui mesmo?

Berenice: Está faltando alguma letrinha...

P: Qual letrinha você acha que está faltando?

Berenice: A letra $d$ e $a$.

P: Mas você já não tinha escrito aqui? Está correto, então?

Berenice: Tá.

A pergunta elaborada pela criança para o seu correspondente (onde você estuda?) apontaria, à primeira vista, o desconhecimento pela representação de nasalização por uma marca gráfica que a ela fora ensinada como representação gráfica de uma consoante: a letra $\mathrm{N}$ na palavra onde, do mesmo modo como não grafara M na palavra bem. Desbordes (1995, p. 177) critica a busca da relação estreita entre o oral e o escrito, ao comentar que "a ideia frequente, ingênua ou erudita, de que a escrita deve refletir o som, de que é preciso 'escrever como se fala', traduz-se, na prática, de um lado, por uma tendência a multiplicar os sinais e, de outro, por uma procura de isomorfismo entre escrito e oral [...]".

Williams (1975, p. 35) informa, do ponto de vista histórico, que na evolução do português o "uso final do M para indicar a nasalização da vogal 
apareceu talvez em monossílabos da prosa legal por imitação da ortografia latina, e.g., com, quem, rem (arcaico), tam. O abandono do $\mathrm{N}$ em favor do M ocorreu no século XIII". Há, contudo, usos também do til. Para Williams (1975, p. 34) "o til foi usado pelo $m$ intervocálico para ganhar espaço num esforço de manter a linha dentro dos limites da margem direita”. Neste caso, foram atiradas ao ar todas as preocupações com a representação fonética, para que fosse cedido lugar ao esforço de configuração da palavra no final da linha, de modo que seu limite fosse respeitado.

Outro aspecto a considerar é a oscilação entre segmentação e aglutinação de palavras, como havia também em textos na história da língua latina (DESBORDES, 1995). Possivelmente, as tentativas de segmentação obedeciam e obedecem a critérios múltiplos - ora relacionados à prosódia, ora aos elementos sintáticos, ora a unidades de sentido, ora a sequências silábicas gráficas correspondentes a sequências silábicas orais. A respeito da escrita não segmentada entre os latinos, afirma Desbordes (op. cit., p. 183) que "pode haver aqui uma intenção de imitar a escritura grega onde a elisão é um fenômeno frequente e normal e onde, de uma forma mais geral, não existe a preocupação de preservar a individualidade das palavras: a regra, em grego, é a scriptio continua, a sucessão ininterrupta das letras".

Os latinos, todavia, já teriam experimentado critérios de segmentação antes de se curvarem à cultura grega e à escrita contínua, a partir no século II d.C. e, por isso, insistiam em valorizar "uma espécie de 'fisionomia' da palavra, que não queriam alterar em função de suas modificações orais, ocasionadas pela vizinhança”" (idem, ibid.). Entendida como configuração gráfica, a fisionomia da palavra incorporaria as letras como unidades, cada qual com sua função a desempenhar na construção dos sentidos.

Na sequência da carta, Berenice registra:

Você t-eirme? (letra $t$, seguida da letra $e$ com til)

(Você tem irmão?)

P: Por que você colocou essa marquinha na palavra tem?

Berenice: É porque nesta palavra tem acentinho.

Enquanto escrevia a palavra irmão, a aluna murmurava (SMOLKA, 1993), tentando fazer a opção por determinadas letras.

P: Por que você escreveu com $e$ a palavra irmão? 
(permaneceu em silêncio).

P: Você acha que é essa letrinha?

Berenice: É (indecisa).

Novamente, Berenice utiliza a palavra tem com a marcação anteriormente empregada em bem, mas não usa o mesmo sinal para grafar a palavra irmão. Aqui opta pelo uso da letra E em substituição a I - caso categorizado, de modo simplista por certas áreas da linguística, como hipercorreção - e novamente da letra E para ocupar a posição destinada ao ditongo nasal ÃO. É de supor, entretanto, que a aluna não se preocupa com a marcação da nasalidade, mas com a inserção de uma vogal na posição que caberia mesmo às vogais. Ela elabora a hipótese de que a letra $M$, tomada aqui como consoante em vez de indicação de nasal, deveria vir sempre acompanhada de uma vogal, como indica sua indecisão diante da questão formulada pela bolsista. É possível anunciar a hipótese de que Berenice não se preocupa apenas com a distinção entre vogais nasais e orais para representá-las, mas toma como referência sua pouca experiência com as configurações gráficas com o sinal til, e tenta conceder a ele uma função específica, uma vez que não o utiliza na palavra irmão. Merece ser novamente ressaltado que não há uniformidade na elaboração de regras para as escolhas. Ora há regras precárias, como o mesmo uso do til em bem e tem, ora isso não se aplica a outra vogal - A, em irmão. A ambiguidade e falta de padronização das escolhas compóem os atos de tentativa de escrita nesse período inicial. $\mathrm{Na}$ sequência, como mostra o trecho a seguir, a aluna volta a fazer escolhas imprevisíveis:

Qomu ceir megão?

Como se chama seu irmão?

P: Por que você escolheu a letra Q para escrever como?

Berenice: Porque co é a letra Q e a letra O! (indecisa) Não, não é com a letra Q não.

P: Como que é então?

Berenice: É com C e O.

P: Por que você escreveu como com a letra U?

Williams (1975) registra várias confusões ortográficas no português arcaico, por exemplo, entre Q e C. Documentos de 1453 indicam o uso 
de QU por C, por exemplo Quo, utilizado em quoall como qual: "1. Uso de $q u$ por $c$ : cinquo por cinco; nunqua por nunca. A. Por causa dessa confusão, quo por vezes foi usado para representar [kW], e.g., quoall [...]" (WILLIAMS, op. cit., p. 34). Berenice empregou $Q O-Q O M O$, também equivalente a $Q U$ em vez de $C O$ para escrever Como. Curiosamente, registra Huber (2006, p. 106), o desaparecimento do "elemento bilabial no qu latino inicial, i.e., passou a $k$, embora se tenha mantido a grafia $q u$ : [...] quomodo > como (escrito também quomo ainda em documentos do séc. XIII)". Berenice omitiu apenas a vogal U, mas manteve QO. Novamente, a grafia contemporânea se aproxima da grafia do português antigo. Mais do que representar fonemas, passam a exercer uma função na configuração gráfica identificadora da palavra.

Ao fazer uma pergunta, a bolsista provocou a reflexão da aluna que, em seguida, substituiu a letra $\mathrm{U}$ pela letra $\mathrm{O}$. Ao escrever a palavra chama, ficou pensativa e disse:

Berenice: Não sei como que escreve chama.

P: Você sabe sim, escreva do seu jeito!

Nesta situação, a aluna aparentemente tenta corresponder um grafema a um fonema, mas a escrita já lhe dera a oportunidade de utilizar letras alternativas como $c, q$ e $k$, de um lado, $o, u$, de outro, ou ainda as demais vogais como equivalentes entre si ( $a$ por $e, u$ por $i$, entre outros), como marcadores de posição. Aqui opta pela letra $\mathrm{Q}$ e por $\mathrm{U}$ para escrever o pronome interrogativo como.

As demais escolhas feitas por Berenice na sequência da carta também receberam comentários, mas, em virtude da sua extensão e detalhamento, serão publicados em outro artigo.

\section{Conclusão}

Não há qualquer intenção em generalizar as hipóteses levantadas, nem mesmo há qualquer indicação de que todas as crianças realizam percursos ou manifestaçôes linguísticas semelhantes. Há que se destacar, todavia, como conclusão, que é possível pensar em ampla diversidade na escolha das letras pelas crianças, em vez de entender essa escolha como ação limitada à relação entre grafemas e fonemas, reduzidos a simples elementos, em vez 
de compreendê-los, tanto uns quanto outros, como unidades portadoras de sentido, como anunciaram Vigostki (2001) e Desbordes (1996). Os caminhos de análise aqui abertos podem se revelar muito ou pouco promissores, mas as evidências nos atos de escrita não podem ser desconsideradas por se tratar de um único sujeito.

\section{Referências}

ABAURRE, M.B.M; FIAD, R.S; MAYRINK-SABINSON, M.L.T. Cenas de aquisição da escrita. Campinas: Mercado de letras, 1997.

BAKHTIN, M. Estética da criação verbal. São Paulo: Martins Fontes, 2003.

DESBORDES, F. Concepções sobre a escrita na Roma Antiga. São Paulo: Ática, 1995.

GOES, M.C.R. A abordagem microgenética na matriz histórico-cultural: uma perspectiva para o estudo da constituição da subjetividade. Cadernos Cedes, Campinas, v. 20, n. 50, p. 9-25, abr. 2000.

GRAUE, M.E.; WALSH, J.D. Investigação etnográfica com crianças: teorias, métodos e ética. Lisboa: Fundação Calouste Gulbenkian, 2003.

HUBER, J. Gramática do português antigo. 2. ed. Lisboa: Fundação Calouste Gulbenkian, 2006.

PARKES, M. Ler, escrever, interpretar o texto: práticas monásticas na Alta Idade Média. In: CAVALLO, G.; CHARTIER, R. História da leitura no mundo ocidental. São Paulo: Ática, 2002. p. 103-122.

SAMPSON, G. Sistemas de escrita: tipologia, história e psicologia. São Paulo: Ática, 1996.

SMOLKA, A.L.B. A dinâmica discursiva no ato de escrever: relações oralidade-escritura. In: SMOLKA, A.L.B.; GOES, M.C.R. (Org.). A linguagem e o outro no espaço escolar: Vygotsky e a construção do conhecimento. Campinas: Papirus, 1993. p. 33-62.

VIGOTSKI, L.S. A construção do pensamento e da linguagem. São Paulo: Martins Fontes, 2001. 
WILliAMS, E. Do latim ao português. Trad. de Antonio Houaiss. Rio de Janeiro: Tempo Brasileiro, 1975.

Recebido em 30 de setembro de 2012.

Aprovado em $1^{\circ}$ de março de 2013. 